\title{
Uso de comunidades virtuais no suporte a portadoras de câncer de mama
}

\author{
The use of virtual communities \\ in the support to patients with breast cancer
}

Myllena Cândida de Melo ${ }^{1}$

Paulo Roberto Vasconcellos-Silva ${ }^{1}$

${ }^{1}$ Instituto Nacional de Câncer. R. Equador 831, Santo Cristo. 20220-410 Rio de Janeiro RJ Brasil. myllena.melo@inca.gov.br

\begin{abstract}
Thinking about virtual communities as a space for interaction and the sharing of experiences, especially among individuals affected by chronic diseases, the scope of this study was to analyze the role and nature of support offered by virtual communities to breast cancer patients. It is a descriptive study with a qualitative approach. For data collection, the Netvizz application was used extracting data from the first five Facebook open breast cancer groups in the year 2016. There were 2921 posts, totaling 1722 comments. For data analysis a word cloud was created through WordArt, and the most recurrent words were discussed in cross-sectional categories: I, confessional, vs. you, interactional; therapeutic process, religiosity and the "Intervention Window." The results show that the support offered in these spaces occurs especially in the informational and emotional spheres, ranging from the diagnosis phase to the control of the disease. The understanding of the significance of the information shared in the virtual communities by women with breast cancer can contribute to the practice of care that is not restricted to the biological and technical approaches, but rather a more comprehensive and effective approach to holistic care.
\end{abstract}

Key words Social networking, Communication in health, Breast cancer
Resumo Pensando nas comunidades virtuais como espaço de interação e compartilhamento de experiências, principalmente entre indivíduos acometidos por doenças crônicas, objetivamos com este estudo, analisar o papel e natureza de suporte oferecido pelas comunidades virtuais às portadoras de câncer de mama. Estudo descritivo com abordagem qualitativa. Para coleta de dados foi utilizado o aplicativo Netvizz, extraindo dados dos cinco primeiros grupos abertos de câncer de mama do Facebook, no ano de 2016. Foram encontradas 2921 postagens, totalizando $1722 \mathrm{co}$ mentários. Para análise dos dados foi criada uma nuvem de palavras através do WordArt, e as palavras mais recorrentes foram discutidas em categorias transversais: Eu Confessional X Você Interacional; processo terapêutico, religiosidade e "Arco de Intervenções". Constatamos, pelos resultados, que o suporte oferecido nestes espaços se dá especialmente nas esferas informacional e emocional, indo desde a fase de diagnóstico até o controle da doença. A compreensão das significações das informações partilhadas nas comunidades virtuais por mulheres com câncer de mama pode contribuir para a realização de práticas de cuidado que não se restrinjam às abordagens de cunho biológico e tecnicista, mas sim numa assistência holística, integral e efetiva.

Palavras-chave Rede social, Comunicação em saúde, Câncer de mama 


\section{Introdução}

Vivemos na era da informação e da comunicação digital, e nesse cenário a internet estabeleceu-se como uma valiosa fonte de informações em saúde, indo desde conselhos de um estilo de vida saudável até o tratamento de doenças, permitindo que o fácil acesso à essas informações transformasse os indivíduos em colaboradores mais ativos e capacitados na gestão de sua própria saúde.

A internet tem provocado radicais transformações nas relações econômico-sócio-culturais. Hoje, qualquer pessoa, com mínima habilidade tecnológica e condição financeira para aquisição de um dispositivo eletrônico, tem acesso a informações anteriormente restritas a pequenas parcelas da população ${ }^{1}$.

Essa acessibilidade, associada a mobilidade e a comunicação livre de barreiras geográficas e em uma escala global, aponta para uma nova configuração cultural, criando inúmeras formas de interação social, reconstruindo e reconfigurando os padrões de relacionamento online, como é o caso das comunidades virtuais.

As comunidades virtuais são fontes de valores que moldaram o comportamento e organização social, caracterizando-se fundamentalmente pela comunicação livre e horizontal, permitindo que cada pessoa encontre a sua própria destinação na internet, formando redes autônomas².

Entre as plataformas utilizadas nesta área, as mídias sociais (fóruns, blogs, grupos do Facebook, Twitter) desempenham um papel cada vez mais importante em vários segmentos, principalmente no âmbito da saúde ${ }^{3}$.

Esses espaços permitem o compartilhamento de informações e conselhos práticos com pares em um formato que muitas vezes é mais acessível do que aqueles divulgados pelos cuidadores e profissionais de saúde 4 .

A expressão "comunidade virtual", então, poderia ser definida como um conjunto de indivíduos que se organizam em torno de uma identidade ou tema afim, como o caso de uma patologia, cuja interação é realizada por meio de plataformas comunicacionais on-line, como o Facebook, onde muitos pacientes compartilham informações e experiências sobre os problemas que enfrentam ${ }^{5}$, além da cooperação e dos processos de colaboraçãó.

Logo, as comunidades virtuais são constituídas a partir de interesses comuns, tornando-se em espaços de aprendizagem não formal, a partir da elaboração do conhecimento em um proces- so cooperativo, privilegiando a co-construção do conhecimento ${ }^{6}$.

A construção do conhecimento é um processo fundamentalmente social e interativo. Perfilhando esta ideologia, têm surgido comunidades de aprendizagem ao longo de todo o mundo. As comunidades de aprendizagem pressupõem três noções essenciais: a existência de um espaço, que pode ou não ser um espaço físico de partilha $\mathrm{e}$ construção das aprendizagens; a existência de um processo de aprendizagem que se suporta no apoio mútuo entre os seus membros e se caracteriza pela colaboração, interação, pertença a um grupo e sentimento de partilha de saberes e experiências e, ainda, pela definição do conceito de aprendizagem como sendo um processo de construção que se edifica ao longo de um percurso ${ }^{7}$.

No enfrentamento de uma doença, principalmente quando crônica, como é o câncer de mama, as comunidades virtuais tornam-se ambientes propícios para o debate e compartilhamento de experiências por pares, logo, transformando-se em comunidades virtuais de aprendizagem.

No cenário global, exceto os cânceres de pele não melanoma, o câncer de mama é o mais comum e frequente entre as mulheres, correspondendo a $25,2 \%$ de todos os tumores malignos femininos, além de ser a primeira causa de morte por câncer entre as mulheres ${ }^{8}$. Para o Brasil, estimam-se 59.700 casos novos de câncer de mama, para cada ano do biênio 2018-2019, sendo o primeiro mais frequente em mulheres em todas as regiões do Brasil, exceto na região Nordeste, onde é o segundo, sendo o câncer de colo de útero o primeiro?.

Atualmente, o câncer de mama não é mais uma doença fatal, mas sim crônica, interferindo diretamente na qualidade de vida das mulheres acometidas, comumente nos quesitos sexual, humor, relações familiares, imagem do próprio corpo e atividades cotidianas, podendo levar à depressão, ansiedade, ideação suicida, insônia e medo, além do isolamento social ${ }^{10}$.

Pensando neste isolamento social, muitos pacientes buscam o espaço virtual, como meio de interação, mesmo que de forma passiva inicialmente, através das páginas e grupos de apoio relacionados à sua doença. Estes espaços, além de proporcionarem informações sobre a doença, prevenção e suporte, trazem esperança para o enfrentamento do problema, seja pelo compartilhamento de experiências, seja pela reconhecimento e identificação de outras na mesma situação.

Diante da reconfiguração social associada a internet e uso das redes sociais, relacionadas prin- 
cipalmente à saúde e doenças, fica evidente a relevância de estudo destes espaços virtuais pelos profissionais de saúde, como estratégia para reduzir a lacuna de conhecimento e deficiências enfrentadas pelas pacientes, não alcançadas ou não ditas nos consultórios, compreendendo possíveis rearranjos e transformações necessárias dos tradicionais paradigmas do sistema de saúde, aprimorando a assistência dos prestadores de cuidados de saúde.

Logo, objetiva-se com este estudo, analisar o papel e natureza de suporte oferecido pelas comunidades virtuais às portadoras de câncer de mama.

\section{Métodos}

Trata-se de uma pesquisa descritiva com abordagem qualitativa. A pesquisa qualitativa trabalha com o universo de significados, motivos, aspirações, crenças, valores e atitudes, o que corresponde a um espaço mais profundo das relações, dos processos e dos fenômenos que não podem ser reduzidos à operacionalização de variáveis ${ }^{11}$.

Para coleta dos dados utilizamos como ferramenta o Netvizz, um aplicativo do Facebook, capaz de extrair dados abertos de diferentes seções da plataforma, como grupos e páginas para fins de pesquisa, identificados através de palavraschave em seus nomes ou descrições, como a usada neste estudo, câncer de mama.

Utilizamos como critérios para seleção, os primeiros cinco grupos de câncer de mama no ranqueamento do Netvizz, abertos e de caráter público, com descrição em português. $\mathrm{O}$ ano de 2016 foi selecionado como período de coleta, para que pudéssemos avaliar as postagens ao longo de todo o ano. Os grupos serão identificados por numeral ordinal, como grupo 1, 2 e assim sucessivamente, garantindo o sigilo e anonimato de seus membros.

Para operacionalização da análise de conteúdo foi usada a ferramenta online conhecida como "nuvem de palavras" (NP), um recurso que permite criar uma imagem de palavras a partir de um determinado texto. Na nuvem aparecem em maior proeminência as palavras que ocorrem com maior frequência no texto. Pode-se escolher diferentes tipos de letra, de disposição das palavras e esquemas de cores para facilitar a visualização. As NP são, portanto, a representação de uma lista hierarquizada visualmente, com fins de classificação $^{12}$.

A presença ou ausência de certos elementos, como palavras e temas, pode ser um fator significativo da análise, assim como a frequência em que aparece dada unidade de registro ${ }^{13}$. A NP atende a necessidade de identificar quais termos são mais discorridos e utilizados ao se debater sobre um tema, possibilitando traçar um mapa de relações entre os termos e os sentimentos expressos por eles.

Todas as postagens e comentários feitos no ano de 2016, nos cinco grupos selecionados, foram copiados para arquivo de texto e retirados numerais, preposições, artigos e pronomes, entre outros elementos gramaticais de limitado valor semântico à análise de conteúdo. A partir daí uma NP foi gerada por meio de algoritmos do website Wordart.com (Figura 1).

Extrapolando o recurso ilustrativo, a NP tem sido ponderada como uma opção à análise de textos em pesquisas qualitativas, sendo considerada uma ferramenta eficaz de comunicação, acrescentando clareza de ideias ${ }^{14}$.

\section{Resultados e discussão}

Os cinco grupos selecionados entre os primeiros no ranqueamento do Netvizz têm como caracte-

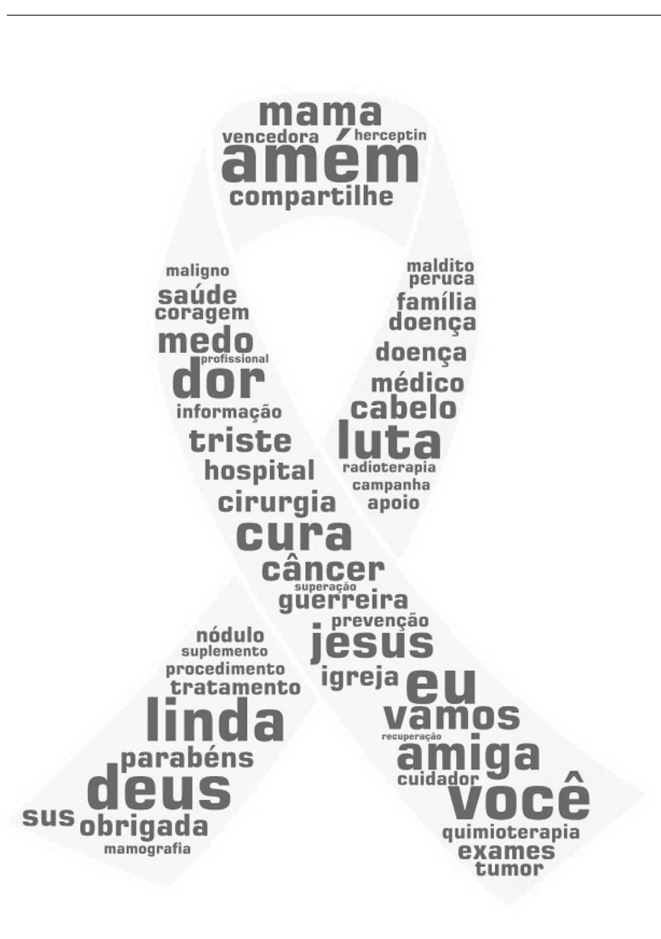

Figura 1. Nuvem de palavras a partir dos comentários dos grupos de câncer de mama do Facebook.

Fonte: Word Art. 
rística comum, terem sido criados por pacientes acometidas pelo câncer de mama. Por serem grupos abertos, qualquer usuário do Facebook pode participar do grupo, seja paciente, familiar, uma pessoa interessada pelo assunto, até profissionais de diversas áreas.

O grupo 1 conta com mais de 2000 membros, foi criado há cerca de 03 anos por uma paciente e administrado pela mesma, que se intitula como ativista na luta contra o câncer e tem como foco $\mathrm{o}$ apoio emocional e religioso de seus membros.

O grupo 2 tem aproximadamente 1400 membros, criado há 07 anos, administrado por 5 membros, dentre estes um do sexo masculino, tipificado como grupo de apoio, com intuito de conscientizar as pessoas do Facebook a utilizarem este meio de interação, para abraçar uma causa nobre.

O grupo 3 conta com mais de 1700 membros, criado há 2 anos por uma professora de Educação Física, sendo destinado a mulheres e homens que já passaram ou estão passando pelo câncer de mama e também para quem apenas se interessa e busca informações sobre o tema. Tido como grupo de apoio, é colocado como um lugar onde seus integrantes podem desabafar, saber como foi cada caso e quais médicos e quais hospitais envolvidos no tratamento.

O grupo 4 criado e administrado por um homem há 4 anos, tem cerca de 1200 membros e traz como referência para o grupo a frase motivacional "A cura vai chegar... e a vida vai continuar!!!".

E por fim, o grupo 5, criado e administrado há 4 anos por uma pedagoga, conta com 74 membros e traz em sua descrição ser um espaço para "testemunhos de curas de câncer de mama, desafios enfrentados no casamento e na vida social, artigos científicos sobre tratamentos e alimentações saudáveis, direitos da mulher com câncer de mama, eventos, passeios, vídeos, implantes mamários, ONG, adaptações ao volante, fotos e tudo que contribuem para o bem-estar da mulher com câncer de mama".

Assim, percebemos que todos os grupos se configuram como ambientes de apoio, em sua maioria emocional, mas também informacional. Variando de 02 a 07 anos de início, criados e administrados desde pacientes mulheres, homens até profissionais da área educacional e da saúde. O número de membros variou bastante, indo de 74 até mais de 2000 membros.

Dentre todos os cinco grupos, foram resgatadas 2921 postagens, totalizando 1722 comentários. A partir destes comentários, foi criada a nuvem de palavras representativa destes, apre- sentando as palavras mais recorrentes (Figura 1), apresentadas e discutidas em categorias transversais como: eu confessional; você interacional; processo terapêutico e religiosidade.

\section{Categorias}

As duas primeiras categorias (Eu confessional) e (Você interacional) foram utilizadas para pontuar esses dois momentos e intenções identificados nos grupos, onde uma mesma paciente pode por ora, em uma postagem e comentário, se aproximar de uma ou de outra condição. Assim, o eu confessional e o você interacional representam locais de fala, de onde parte a comunicação e para que, quem e como se direciona.

A terceira categoria (Processo terapêutico) refere-se ao tratamento do câncer, propriamente dito e seus efeitos colaterais, desde diagnóstico, cirurgia, radioterapia, quimioterapia, até o acompanhamento de controle da doença.

A quarta categoria apresentada, (Religiosidade), discute o apoio encontrado nas comunidades virtuais, vinculado à religião e fé.

E, por fim, a categoria (Arco das Intervenções), demonstra o suporte oferecido pelas comunidades no decorrer de todo o processo saúde-doença.

\section{Eu confessional}

Nessa categoria, o "Eu confessional" é usado para explicitar o uso destes espaços para relatos confessionais das pacientes acometidas pela doença, narrativas sobre seus processos de saúde/ doença e enfrentamento do câncer de mama.

Por conseguinte, a partir desta nuvem de palavras, inferimos inicialmente, pela recorrência do pronome EU e dos verbos na primeira pessoa, que muitas mulheres usam esse espaço para fazerem seus relatos sobre a doença, compartilhando suas experiências.

$\mathrm{Na}$ contemporaneidade, as subjetividades do adoecimento são atravessadas pelos avanços tecnológicos, como mostra o compartilhamento de várias esferas da vida em plataformas digitais como Facebook. Hoje observa-se que a exposição do tratamento oncológico nas redes sociais pode gerar uma nova forma de enfrentamento da doença, onde antes eram característicos o isolamento e silêncio ${ }^{15}$.

Como mostrado nos exemplos a seguir, era explicitamente notável que o compartilhamento de tais experiências visava não apenas a expressão de seus sentimentos, mas a possibilidade de atingir outras pessoas com suas palavras e, assim, 
quem sabe, ajudá-las a passar pelos seus próprios processos $^{16}$.

Ainda faço quimioterapia, e lembro da primeira, e te falo: amanhã é a terceira. O q eu faço? Bom, é tenso pq tenho q chegar muito cedo, a medicação só chega após as 9, etc. O q quero dizer é: desde a primeira, mesmo diante da incerteza, procurei ficar tranquila. ..., eu olhava para o lado via pessoas chorando (um pouco antes de começar, uma senhora parou perto de mim e começou a chorar, dizendo $q$ já tinha me visto, e como eu me sentia sabendo $q$ eu e ela perderíamos nossos cabelos). Meninas, pensem em coisas boas, nunca senti nada, depois saio andando normal, os dias até então, tem sido normais (as vezes um enjoo, um pouco de cansaço, nada q o medicamento não alivie!).

Amiga, comigo foi um pouco complicado, cada caso é um caso. Pois eu tomei o herceptin junto e também 5 doses de vacina, mas ela é muito mais fraca, sim, tenha fé, passa rápido!!!! Já fiz todas as vermelhas só falta uma branca dia 13 de fevereiro, aí vou operar depois de 40 dias. Não se assuste!!!!! Se anime jesus é contigo se precisar de mim tô aqui sempre!!! Meu grau era 3 B, localmente avançado, ductal invasivo e estou na reta final...

\section{Você interacional}

Apesar de ser claro que o processo interacional perpassa os espaços das comunidades virtuais, a expressão "Você interacional" foi aqui assim nomeada para representar os momentos em que as pacientes buscam informações e suporte de outras, questionam tratamento e efeitos colaterais, interagem almejando o conhecimento pela experiência de outras.

A frequência do pronome VOCÊ, também demonstra interesse nas experiências de outras pacientes, visto que muitas usuárias ainda estão no caminho para definição do diagnóstico do câncer de mama, buscando por outras pacientes que tenham tido sintomas semelhantes, referem dúvidas quanto aos efeitos sentidos no tratamento ou questionam a conduta médica, conforme exemplos abaixo de comentários extraídos.

Sinto dor nos bicos dos seios...no banho não consigo nem tocar. Tô preocupada alguém sabe me dizer se já passou por isso??

Olá, tomo tamoxifeno faz 4anos, tive câncer de mama com 28 anos e estou com espessamento de endometrio, vou fazer a terceira histeroscopia agora cirúrgica. Mais alguém com esse problema?

Comecei a tomar tamoxifeno faz 5 meses. não tenho muitos efeitos colaterais. fiz mastectomia da mama direita e agora em setembro vou retirar a mama esquerda para prevenção e reconstrução da mama direita. alguém fez cirurgia tomando tamox. li a bula e me assustou um pouco. adorei ler os depoimentos precisava disso...

As informações, situações e dúvidas compartilhadas inteiram os participantes sobre o diagnóstico e o tratamento, podendo torná-los mais aptos para práticas de autocuidado. Ao compartilhar informações e experiências, o cidadão pode ainda desenvolver práticas de promoção da saúde e de melhoria na qualidade de vida ${ }^{5}$.

Nesse sentido, o Facebook pode ser entendido como uma ferramenta ativa no processo de construção social do mundo contemporâneo, uma vez que possibilita a interação entre pessoas de diversas partes do mundo, co-construindo e disseminando conceitos referentes ao momento em que vivem. Também nesse sentido, as redes sociais virtuais podem ser consideradas ferramentas mantenedoras de discursos, narrativas dominantes ${ }^{16}$.

Levando em consideração o contexto cultural em que vivemos, em que o câncer é visto como sinônimo de morte e outras perdas, é preciso estar atento para o fato de que o tratamento quimioterápico, seja pré ou pós-operatório, provoca reações de luto pelo impacto nas mudanças corpóreas. A queda de cabelo, por exemplo, muitas vezes expressa como maior preocupação, pode evidenciar o que essa perda representa na psique da paciente: a diminuição da feminilidade, o estigma do câncer, o estigma da morte, a rejeição do sentimento de piedade, o preconceito, autodefesa, uma fase de rejeição ${ }^{16}$.

Entretanto, é importante mencionar que o uso do Facebook pode beneficiar ou afetar a vida da pessoa, uma vez que, para alguns, essa plataforma de socialização pode aumentar sua satisfação com a vida e o apoio social percebido, enquanto para outras pessoas pode ser um fator desencadeante de estresse, ansiedade, depressão, medo entre outras ${ }^{17}$.

Amiga boa noite...minha querida, eu raspei antes pois já sabia que isso iria acontecer...infelizmente!!! mas não fique triste!!! o cabelo depois cresce...e com força e ainda mais bonito!!!! vc é linda e isso será apenas uma fase na sua vida

$V c$ é linda com cabelo ou sem cabelo

É verdade querida, só quem já passou por isso sabe o quanto é importante ter pessoas queridas ao nosso lado, juntas sempre!!!

Eu tô com um caroço na mama e tô com muito medo. Minha mama dói, meu bico do peito queima, será que é normal?

Sentimentos negativos ante a experiência de estar com câncer de mama foram observados em 
alguns relatos de mulheres, como exemplo abaixo, ratificando o impacto negativo que a doença traz no curso de vida de algumas mulheres, resultando em sentimentos de tristeza, decepção e dor ${ }^{18}$.

Só quem passa por essa doença sabe o quanto é difícil pra nós, ficar sem dormir, sentir dor, ter que sorrir mesmo querendo chorar eu tô forte não sei até quando

Relatando o seu dia a dia, incluindo sua rotina de tratamento e suas relações, as autoras expunham os diversos aspectos envolvidos no período em que viviam e, sem ignorar as dificuldades encontradas, expressavam claramente sua vontade de olhar para o lado bom, se autodenominando de guerreiras, mulheres fortes, divas e incentivando outras mulheres a também utilizar essa perspectiva ${ }^{16}$.

Forças guerreira, Deus é contigo!

Linda e poderosa bjs. Boa noite

Somos fortonas, e temos a ... para nos inspirar e incentivar

linda!!! guerreira incrível! parabéns...te amo viu...

\section{Processo terapêutico}

Nessa categoria, percebe-se claramente o uso das comunidades virtuais como espaço de interação entre pacientes em mesma condição, trazendo em suas narrativas, a história do processo de saúde-doença, perpassando diferentes fases do processo terapêutico, desde o diagnóstico até o controle, enfatizando questões como os sintomas, representados nas palavras (SINTO, DOR), o tratamento proposto (TRATAMENTO, CIRURGIA) e o uso de medicamentos (TOMO).

A narrativa dominante relacionada ao câncer parece estar imensamente atrelada a conceitos considerados negativos, como morte, hospitalização, depressão, mutilação, sofrimento, quimioterapia, perda de cabelo, dentre outros. Muito embora, com os avanços médico-tecnológicos, as taxas de sobrevivência e cura tenham aumentado muito. O estigma que a doença carrega ainda tem muito impacto naqueles que são diagnosticados e no modo como encaram o tratamento que se segue.

A queimadura da radioterapia é muito dolorida, minha mãe fez.

Esses médicos são muito negativos gente, credo.

Passei por esse msm procedimento E quando comecei a quimioterapia o tumor estava com 20 centímetros foi na minha mama esquerda e na primeira sessão que fiz diminuiu pra 9, na segunda sessão pra 7 na terceira pra 5 e assim foi diminuindo. Hj já fiz a cirurgia respondi muito bem ao tratamento
Miga vc fez quimioterapia? não demora tanto assim. Tem q reclamar

Pois e me ligaram pq minha reconstrução seria após a cirurgia e ai falaram que iam comprar o expansor e até agora nada!

Outro ponto interessante é que, embora nem sempre soubessem precisar as drogas que usavam na quimioterapia, as mulheres reconheciam a medicação por meio das cores, o que as auxiliava a antecipar e lidar com os efeitos do tratamento. Assim, se uma mulher dizia que a quimioterapia "era da branca", então as que já haviam passado pelo tratamento sabiam que essa era uma medicação mais fraca, com menor toxicidade, diferente da vermelha, que provocava inclusive a queda do cabelo ${ }^{19}$.

A quimioterapia branca realmente é mais fraca tem algum efeito começo a minha dia 01 a primeira branca.

\section{Religiosidade}

Outra perspectiva bastante recorrente é o apoio vinculado à religião (fé, Deus, Jesus Cristo), desvelando uma percepção mais ampliada de autocuidado, fé e otimismo, impulsionando a produção de rearranjos para a manutenção do cotidiano, mesmo diante da compreensão da finitude imposta pelo câncer ${ }^{20}$.

O importante é acreditar e se entregar nas mãos de Deus e confiar também em si próprio

Oi bom dia!!! Eu tb descobri um câncer em 2016, e hj estou bem, acredite Deus faz o milagre da cura!!!! Deus abençoe a todos!!!

Quando o manejo da situação está além das condições dessas mulheres, o enfrentamento se apresenta muito mais como uma forma de lidar com a situação do que propriamente de resolvê$\mathrm{la}^{21}$.

Pesquisas recentes têm se reportado ao enfrentamento religioso/espiritual, o qual retrata o uso da espiritualidade, da religião ou da fé para lidar com o estresse e os problemas de vida de indivíduos portadores de enfermidades crônicas ${ }^{22}$. Os fatores religiosos e espirituais têm sido relacionados a diversos aspectos positivos da adaptação ao diagnóstico e ao tratamento do câncer, indicando sua importância para a saúde e recuperação dos indivíduos acometidos por enfermidades crônicas ${ }^{20}$.

Em suma, é importante reconhecer que, em momentos de sofrimento, os pacientes oncológicos podem recorrer à fé e às crenças religiosas como fonte de alívio e conforto ${ }^{23}$.

Eu tomo e pra mim faz efeitos colaterais tenho todos os sintomas é horrível mas tenho 50\% 
de chance de ã voltar e graças a deus em dezembro vai fazer 5 anos ta quase chegando hehehehehe obgd meu deus

Eu também tomo há 3anos. Sinto alguns desses sintomas. Senti muitas dores nas articulações mas com as vibrações feitas no centro espírita não sinto mais graças a deus

Amém Deus e maior que Jesus te abençoe Jesus É força É paz É amor saúde alegria perseverança confiança É fé É sabedoria direção prospectiva de evolução carinho que Deus te abençoe tenha um ótimo sábado abençoado

Deus não falha seus planos são sempre maravilhosos

Bom, eu fiz a quimioterapia sem pensar q era quimioterapia, foquei na apostila e tentei estudar. Uma Sra me disse, antes de eu entrar (não estou aqui para falar de religião): qdo vc entrar e estiver lá, pense: estou recebendo o sangue de Jesus, e nele está a minha cura. Isso me confortou (não sou muito religiosa, estou aprendendo a ser). Bom, eu tb quis dividir isso. Amanhã tenho outra e vou ficar vendo seus vídeos. Um bj enorme!

\section{Arco das Intervenções}

Constatamos, através das postagens e comentários obtidos, que o suporte oferecido pelas comunidades virtuais às portadoras de câncer de mama se dá especialmente nas esferas informacional e emocional, perpassando todo o processo saúde-doença, representado em um "Arco de Intervenções" (Figura 2), indo desde a fase de diagnóstico até controle da doença.
$\mathrm{Na}$ fase inicial, diagnóstica, as principais questões envolvidas são o acolhimento, indicação profissional e o propósito informacional. Mulheres com suspeita de câncer de mama ou em fase inicial do processo de doença buscam apoio nestas comunidades virtuais, tendo como referência o relato de pacientes que já passaram desta fase.

Durante o processo terapêutico em si, cirurgia, quimioterapia, radioterapia, surgem as dúvidas quanto aos efeitos colaterais e prognóstico esperado. Nesse momento há a troca de experiências, comparação de situações vivenciadas e medidas para superação deste momento.

Já na etapa de controle da doença, há o relato otimista de quem venceu o câncer, teve resiliência e paciência para enfrentar os percalços do trajeto e ainda a oferta afetiva e solidária destas mulheres para com outras que estão em início de tratamento ou etapa anterior, confortando e mostrando exemplos positivos e vitoriosos.

\section{Conclusão}

Graças à conectividade a todo tempo e lugar proporcionados pela internet, nota-se um aumento e expansão das redes sociais e comunidades virtuais no âmbito da saúde e, principalmente, de doenças crônicas, como o câncer, permitindo nestes espaços de interação que indivíduos com problemas de saúde similares compartilhem suas experiências e se apoiem mutuamente, na troca de insights e reflexões sobre seu processo saú-

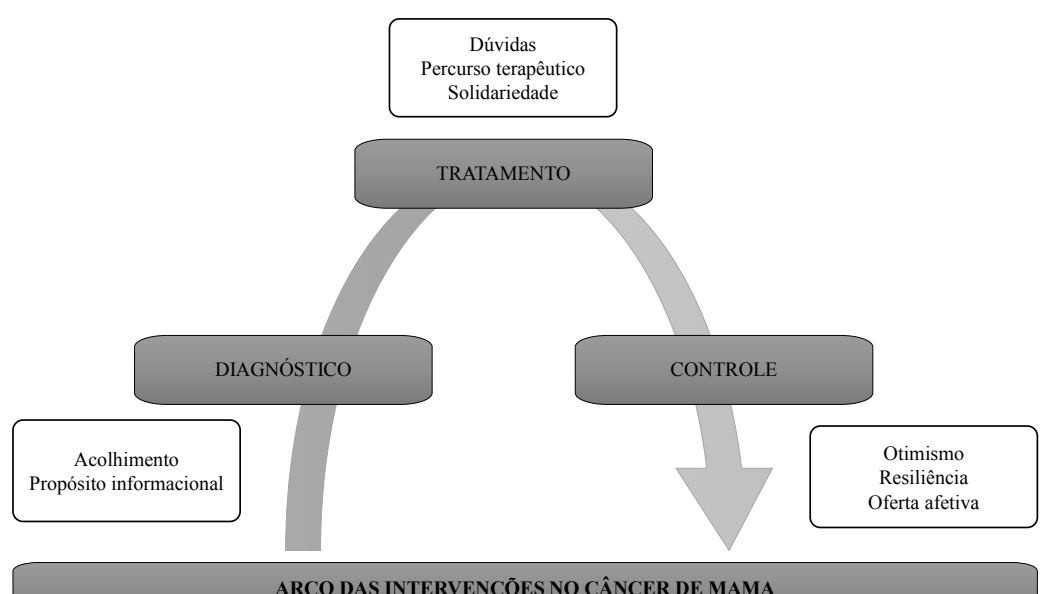

Figura 2. Arco das intervenções no câncer de mama. 
de-doença, que nem sempre são alcançáveis nos consultórios pelos profissionais de saúde.

Percebemos que as significações das informações partilhadas nas comunidades virtuais por mulheres com câncer de mama são complexas, mas sua compreensão pode contribuir para a realização de práticas de cuidado que não se restrinjam às abordagens de cunho biológico e tecnicista, mas sim numa assistência holística, integral e efetiva.

\section{Colaboradores}

PR Vasconcellos-Silva participou da concepção do projeto e revisão crítica do conteúdo intelectual; MC Melo da redação do artigo, análise, interpretação dos dados e aprovação final da versão a ser publicada. 


\section{Referências}

1. Pereira Neto AF, Paolucci R, Daumas RP, Souza RV. Avaliação participativa da qualidade da informação de saúde na internet: o caso de sites de dengue. Cien Saude Colet [revista na Internet]. junho de 2017 [acessado 2017 Nov 22]; 22(6):1955-68. Disponível em: http://www.scielo.br/pdf/csc/v22n6/1413-8123csc-22-06-1955.pdf

2. Castells M. A Galáxia Internet: reflexões sobre a Internet, negócios e a sociedade. Rio de Janeiro: Zahar; 2003.

3. Fox S, Duggan M. Health Online 2013 [Internet]. 2013 [acessado 2017 Abr 21]. Disponível em: http://www. pewinternet.org/2013/01/15/health-online-2013/

4. Thoër C. Les espaces d'échange en ligne consacrés à la santé: de nouvelles médiations de l'information santé. Collect Santé Société [revista na Internet]. 2012 [acessado 2018 Jan 30]; 55-92. Disponível em: http://extranet. puq.ca/media/produits/documents/2136_D3521-FP. pdf

5. Pereira Neto A, Barbosa L, Silva A, Dantas MLG. O paciente informado e os saberes médicos: um estudo de etnografia virtual em comunidades de doentes no Facebook. Hist Cienc Saude Manguinhos [revista na Internet]. 2015 [acessado 2017 Nov 22]; 22(Supl.):16531671. Disponível em: http://www.scielo.br/pdf/hcsm/ v22s0/0104-5970-hcsm-22-s1-1653.pdf

6. Mussoi EM, Flores MLP, Behar PA. Comunidades virtuais - um novo espaço de aprendizagem. IX Ciclo Palestras sobre Novas Tecnol na Educ [Internet]. 2007 [acessado 2015 Abr 22]; Disponível em: http://www. cinted.ufrgs.br/ciclo9/artigos/8aEunice.pdf

7. Catela H. Comunidades de aprendizagem: em torno de um conceito. Rev Educ [revista na Internet]. 2011 [acessado 2017 Dec 16]; XVIII(2):31-45. Disponível em: http://revista.educ.ie.ulisboa.pt/arquivo/vol_XVIII_2/ artigo2.pdf

8. Stewart BW, Wild CP. World cancer report 2014. World Heal Organ [Internet]. 2014 [acessado 2016 Abr 14];12. Disponível em: http://www.videnza.org/wp-content/ uploads/World-Cancer-Report-2014.pdf

9. Instituto Nacional de Câncer. Estimativa 2018: incidência de câncer no Brasil [Internet]. Rio de Janeiro; 2017 [acessado 2018 Abr 4]. Disponível em: http://www1. inca.gov.br/inca/Arquivos/estimativa-2018.pdf

10. Simeão SFAP, Landro ICR, De Conti MHS, Gatti MAN, Delgallo WD, De Vitta A. Qualidade de vida em grupos de mulheres acometidas de câncer de mama. Cien Saude Colet [revista na Internet]. 2013 [acessado 2016 Ago 8]; 18(3):779-788. Disponível em: http://www.scielo.br/pdf/csc/v18n3/24.pdf

11. Minayo MCS. O desafio do conhecimento: pesquisa qualitativa em saúde. 14ª ed. São Paulo: Hucitec; 2014.

12. Lemos LMP. Nuvem de tags como ferramenta de análise de conteúdo: uma experiência com as cenas estendidas da telenovela Passione na internet. Lumina [revista na Internet]. 2016 [acessado 2017 Abr 19]; 10(1). Disponível em: https://lumina.ufff.emnuvens. com.br/lumina/article/view/447/426

13. Bardin L. Análise de Conteúdo. São Paulo: Edições $70-$ Brasil; 2011
14. Mckee S. Usando nuvens de palavras para apresentar seus dados qualitativos [Internet]. 2014 [acessado 2016 Mar 22]. Disponível em: https://www.surveygizmo. com/survey-blog/what-you-need-to-know-when-using-word-clouds-to-present-your-qualitative-data/

15. Moura MCG, Germano IMP. Mulheres diagnosticadas com câncer de mama e redes sociais virtuais: narrativas sobre o adoecer na era do compartilhamento virtual. Encontros Univ da UFC [revista na Internet]. 2017 [acessado 2017 Nov 16]; 1(1):2167. Disponível em: http://www.periodicos.ufc.br/eu/article/ view/14751/13438

16. Santos LG, Bonotto ACP. O Facebook como espaço de construção social: reconstruindo as narrativas sobre o câncer de mama. Nov Perspect Sistêmica [revista na Internet]. 2015 [acessado 2017 Nov 16]; 24(51):67-82. Disponível em: http://www.revistanps.com.br/index. php/nps/article/view/175/150

17. Navarro Oliva EIP, Guzmán Facundo FR, Álvarez Bermúdez J, Silva Gherardi Donato EC. Uso de Facebook, estrés percibido y consumo de alcohol en jóvenes universitarios. Cien Saude Colet [revista na Internet]. 2016 [acessado 2017 Nov 16]. Disponível em: http://www. cienciaesaudecoletiva.com.br/artigos/uso-de-facebook-estres-percibido-y-consumo-de-alcohol-en-jovenes-universitarios/16026

18. Ramos SWR, Sousa FS, Santos TR, Silva Junior WR, França ISX, Figueiredo GCAL. Sentimentos vivenciados por mulheres acometidas por câncer de mama. J Heal Sci Inst [revista na Internet]. 2012 [acessado 2017 Nov 16]; 30(3):241-248. Disponível em: https:// www.unip.br/comunicacao/publicacoes/ics/edicoes/2012/03_jul-set/V30_n3_2012_p241a248.pdf

19. Almeida DR, Gonçalves TR. "Mãos Dadas": experiência da doença em um grupo de apoio ao câncer de mama. Revista Prâksis [revista na Internet]. 2015 [acessado 2017 Nov 16]; 2:133-145. Disponível em: http:// periodicos.feevale.br/seer/index.php/revistapraksis/ article/view/400/1626

20. Machado MX, Soares DA, Oliveira SB. Significados do câncer de mama para mulheres no contexto do tratamento quimioterápico. Physis Rev Saúde Coletiva [revista na Internet]. 2017 [acessado 2017 Nov 16]; 27(3):433-451. Disponível em: http://www.scielo.br/scielo.php?script=sci_arttext\&pid $=$ S0103-73312017000300433\&lng=pt\&tlng=pt

21. Veit CM, Castro EK. Coping religioso/espiritual em mulheres com câncer de mama. Arq Bras Psicol [revista na Internet]. 2013 [acessado 2017 Nov 16]; 65(3):421435. Disponível em: http://pepsic.bvsalud.org/pdf/ arbp/v65n3/08.pdf

22. Gonzalez P, Nuñez A, Wang-Letzkus M, Lim J-W, Flores K, María Nápoles A. Coping with Breast Cancer: Reflections from Chinese-, Korean-, and Mexican-American Women. Heal Psychol [revista na Internet]. 2016 [acessado 2017 Nov 16]; 35(1):19-28. Disponível em: https://www.ncbi.nlm.nih.gov/pmc/ articles/PMC4695243/pdf/nihms724473.pdf 
23. Thuné-Boyle IC V, Stygall J, Keshtgar MRS, Davidson TI, Newman SP. Religious coping strategies in patients diagnosed with breast cancer in the UK. Psychooncology [revista na Internet]. 2011 [acessado 2017 Nov 16]; 20(7):771-782. Disponível em: http://www.ncbi.nlm. nih.gov/pubmed/20878874

Artigo apresentado em 31/01/2018

Aprovado em 06/03/2018

Versão final apresentada em 30/05/2018 